\title{
Cognitive-Behavioral Therapy for Insomnia: A Review of the Treatment Effects on Suicide
}

\author{
Kyunga Park ${ }^{1}$, Sooyeon Suh ${ }^{1,2}$ \\ ${ }^{1}$ Department of Psychology, Sungshin Women's University, Seoul, Korea \\ ${ }^{2}$ Department of Psychiatry, Stanford University, Stanford, CA, USA
}

\author{
불면증을 위한 인지행동치료: 자살 위험성 경감 효과에 대한 고찰 \\ 박경아 ${ }^{1}$, 서수연 ${ }^{1,2}$ \\ 성신여자대학교 심리학과 ${ }^{1}$, 스탠포드대학교 의과대학 정신과 ${ }^{2}$
}

\author{
Received November 30, 2017 \\ Revised December 20, 2017 \\ Accepted December 21, 2017 \\ Address for correspondence \\ Sooyeon Suh, $\mathrm{PhD}$ \\ Department of Psychology, \\ Sungshin Women's University, \\ 2 Bomun-ro 34da-gil, \\ Seongbuk-gu, Seoul 02844, Korea \\ Tel: $+82-2-920-7215$ \\ Fax: +82-2-920-2040 \\ E-mail: alysuh@sungshin.ac.kr
}

Insomnia has been identified as a risk factor for suicide. Apart from its indirect influence on suicide risk through comorbid psychiatric illnesses, there is also strong empirical evidence that insomnia is an independent risk factor for suicide. Insomnia may affect suicide through different mechanisms, such as mood dysregulation, hopelessness, impulsivity, and sleep deprivation. Cognitive-behavioral therapy for insomnia (CBTI) is an evidence-based, non-pharmacological treatment that is effective in treating both primary and comorbid insomnia disorder. Treatment effects of CBTI can be extended to alleviate suicidality by improving sleep disturbance. Through a literature review, we summarize available data which suggests that CBTI may decrease suicidality risk, and provide clinical implications about utilizing CBTI for high risk suicidal patients.

J Sleep Med 2017;14(2):47-54

\section{서 론}

세계보건기구(World Health Organization)에 의하면 매 년 80만 명에 가까운 사람이 자살로 사망하고, 자살로 인한 사 망은 전체 사망 원인의 $1.4 \%$ 에 해당한다. ${ }^{1}$ 대한민국은 2016 년에 인구 10 만 명당 25.6 명이 자살로 사망하였고, 이는 경제 협력개발기구(Organization for Economic Cooperation and Development) 회원국 평균 12.0 명의 2 배에 해당하는 수치 이다. ${ }^{2}$ 자살 시도가 미수에 그치는 경우까지 고려한다면 자 살에 대한 예방적인 접근과 자살 고위험군에 대한 근거 기 반의 효과적인 개입이 중요한 시점이다.

자살과 수면 문제의 관련성은 이미 여러 연구에서 확인되 었다. ${ }^{3-6}$ 정신질환에 동반된 수면 문제가 자살의 위험성을 높 이기도 하고, 정신질환과 수면 문제가 공존하는 경우 수면

This is an Open Access article distributed under the terms of the Creative Commons Attribution Non-Commercial License (http://creativecommons.org/licenses/by-nc/4.0) which permits unrestricted non-commercial use, distribution, and reproduction in any medium, provided the original work is properly cited.
문제가 없을 때보다 자살 행동의 위험이 유의하게 1.99 배 높 다고 보고되었다. ${ }^{7}$ 일본에서 15,597 명을 대상으로 14 년간 장기 추적한 코호트 연구에서는 수면 유지의 어려움과 자살 위험 간의 관계를 확인하였다. ${ }^{8}$ 불면증은 자살 위험이 높은 정신 질환인 우울장애나 알코올사용장애에서도 흔히 동반되어 나타나는 증상으로, 우울장애나 알코올사용장애를 지속 혹 은 악화시켜 자살 위험을 높이는 간접적인 역할을 할 수 있다. 또한 최근에는 선행 연구를 통해 불면증과 자살의 독립적인 관계를 확인하였는데, 우울의 영향을 통제하고도 불면증과 자 살 사고 간의 유의한 관계를 확인하였고, ${ }^{9-11}$ 메타분석에서도 수면 문제와 자살은 우울 증상과 상관없이 독립적인 관계를 보였다. ${ }^{12}$

수면 문제는 우울장애, 조현병, 알코올 남용, 연령, 교육 수 준, 사회적 고립, 만성 질병 등 이미 잘 알려진 자살의 위험 요인에 비해 개입이 비교적 용이한 특징이 있다. 그러나 실 제로 위험 요인에 대한 개입이 자살 위험을 낮출 수 있는지에 대해서는 연구를 통한 근거가 요구되며, Linehan은 자살 행 
동의 예방을 위해 경험적으로 지지할 수 있는 개입의 부재 를 지적하였다. ${ }^{13}$ Glenn 등도 자살 행동의 위험 요인을 밝힌 연구들을 통해 실제 자살을 예측 및 예방할 수 있는 가능성 이 증가하였는지에 의문을 표하였다. ${ }^{14}$ 본 종설에서는 기존 문헌에 대한 고찰을 통해 불면증의 비약물적 치료인 불면증 을 위한 인지행동치료에 대한 소개 및 자살 고위험군을 대 상으로 한 수면 문제에 대한 개입이 자살 위험성을 낮추는 데 효과가 있는지 살펴보고자 한다.

\section{본 론}

\section{불면증을 위한 인지행동치료 소개}

불면증을 위한 인지행동치료는 Spielman의 3-P 모델을 기반으로 만들어진 행동요법 및 인지요법으로 구성되어 있 다. ${ }^{15} 3-\mathrm{P}$ 모델이란, $\mathrm{P}$ 로 시작하는 세 가지 요인으로 인해 만 성 불면증의 기전을 설명하는 모델로, 소인적 요인(predisposing factors), 유발 요인(precipitating factors), 그리고 지속 요인(perpetuating factors)으로 구성되어 있다(Fig. 1). 소인 적인 요인은 생물학적 혹은 심리적 취약성으로, 개인이 타고 나는 요인들을 의미한다. 예민한 성격, 여성, 불면증에 대한 가족력과 같은 요인들을 소인적인 요인이라고 하지만, 기본 적으로는 소인적 요인만으로는 불면증이 발생하지 않는다. 유발 요인은 사람들이 경험하는 스트레스 사건(예를 들어, 시 험, 업무 스트레스, 가까운 가족의 죽음, 대인관계 갈등, 출 산, 이사 등)으로 인해, 단기적으로 불면증을 유발하는 요인 들이다. 대부분의 경우는 시간이 지남에 따라 불면증을 유발 한 스트레스 사건이 해결이 되면서 불면증 증상 또한 사라진 다. 그러나 단기 불면증 증상을 경험한 사람들 중 일부는 만 성 불면증으로 발전하는 경우가 있다. 특히, 잘못된 수면 습 관이나 수면에 대한 역기능적인 생각이 불면증을 악화시키

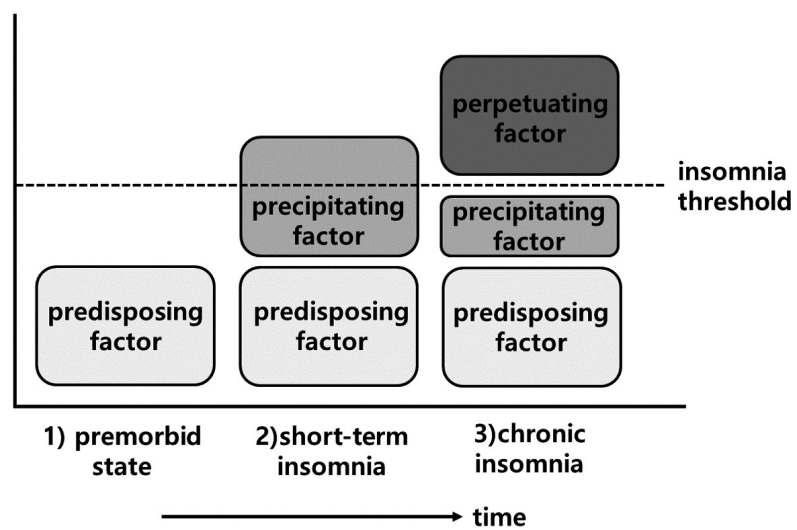

Figure 1. 3-P Model of insomnia. Adapted from Suh. Case Study Book of Cognitive-Behavioral Therapy for Insomnia 2017;6-9, with permission of sigmapress. ${ }^{23}$
고 유지시키는 요인이 된다. 3-P 모델에서는 이런 역기능적 인 생각과 행동들을 지속 요인이라고 부르며, 불면증을 위한 인지행동치료는 이런 지속 요인들을 수정하고 제거하여 불 면증 증상을 완화하는 것을 목표로 한다.

불면증을 위한 인지행동치료는 행동 및 인지요법으로 구 성되어 있으며, 4 8회기로 구성된 단기 심리치료이다. 보통 불면증을 위한 인지행동치료는 수면 교육 및 수면 위생, 자 극 조절, 수면 제한, 이완요법, 및 인지치료로 구성되어 있 다. ${ }^{16}$ 현재 자극 조절, 수면 제한 및 인지치료는 단독으로도 사용할 수 있는 근거 기반 치료로 인정을 받았으며, 보통 수 면 위생 및 이완요법은 부가적인 치료법으로 사용된다. ${ }^{16}$ 광 치료는 모든 환자에게 적용되지는 않지만, 불면증과 자주 동 반하는 지연된 수면위상증후군(delayed sleep phase syndrome)에 해당되는 일주기 리듬 장애 환자에게 사용된다. 특히, 높은 밝기의 빛(>2,000 럭스)은 수면 위상을 당겨주는 기능을 하여, 수면 잠복기를 감소시켜 주기 때문에 수면 개 시 불면증 환자에게 많이 사용된다. ${ }^{17,18}$

불면증 치료 항목의 기본적인 내용은 Table 1 을 참고한다. 보통 자살 위험성이 높은 환자들은 수면 박탈을 유발하면 자 살 생각이 증가할 수 있기 때문에 수면 제한요법은 자살 고 위험군 환자에게는 잘 사용하지 않는 요법이다.

\section{불면증이 자살로 이어질 수 있는 기제}

여러 연구를 통해 우울 등의 변인을 통제한 후에도 불면증 과 자살의 독립적인 관계가 확인되었다. 실제로 불면증과 자 살 사이에 유의한 관계가 존재하여 자살 위험을 낮추기 위해 불면증에 개입하고자 한다면 불면증이 어떤 기제를 통해서 자살 위험을 높이는지에 대한 이해가 필요하다. ${ }^{19}$ 불면증은 주로 야간에 발생하는 수면에 관한 장애이지만 불면증으로 인한 영향은 주간에도 지속되고 불면증 환자들은 이로 인한 어려움을 호소한다. 자살 사고나 자살 행동 등은 주간에 가능 한 것이기 때문에 불면증이 직접적으로 자살 위험을 높이기 보다는 불면증으로 인해 영향을 받는 정서적, 인지적, 생물 학적 요인 등이 자살 위험을 높이는 데에 기여한다고 보고 연 구를 통해 검증하는 것이 보다 타당할 것이다. 본 종설에서 는 불면증이 자살로 이어질 수 있는 기제로써 불면증으로 인 한 정서적, 인지적 영향과 수면 시간의 변화를 살펴보고자 한다.

수면 문제로 인한 정서 조절 실패(Mood dysregulation)

정서 조절에 관한 기존의 연구는 주로 정신질환의 발생, 지 속, 치료에 있어 정서 조절 혹은 정서 조절의 실패가 어떤 역 할을 하는지 확인하기 위한 목적으로 진행되어 왔다. ${ }^{20}$ 예를 들어, 비효율적인 정서 조절은 심각한 우울 증상 및 문제 행 
Table 1. Cognitive-behavioral therapy for insomnia treatment components

\begin{tabular}{ll}
\hline Treatment components & Contents \\
\hline Sleep education & $\begin{array}{l}\text { Psychoeducation about sleep stages (NREM and REM) and the two process model of sleep regulation } \\
\text { (homeostatic process \& circadian process). } \\
\text { Sleep hygiene } \\
\text { Introduce several rules for more effective sleep. For example, avoiding excessive alcohol intake before going } \\
\text { to bed, smoking and limiting strenuous exercise, caffeine intake } 6 \text { hours before sleep and nap time, etc. }\end{array}$ \\
Stimulus control & $\begin{array}{l}\text { Suggest rules to relearn the association between sleep and the bed. For example, going to bed only when sleepy, } \\
\text { leaving bed when unable to sleep and avoiding other activities besides sleep and sex in bed. }\end{array}$ \\
Sleep restriction & $\begin{array}{l}\text { Restrict time in bed in order to increase sleep efficiency above } 85 \% \text { (actual sleep time/time in bed) } \\
\text { Relaxation techniques } \\
\text { Practice progressive muscle relaxation, breathing techniques or autogenic training to decrease physical tension } \\
\text { and promote relaxation. } \\
\text { Mognitive therapy } \\
\text { Modify dysfunctional beliefs about sleep. For example, having the client keep a sleep diary if they believe they } \\
\text { require } 8 \text { hours of sleep to collect evidence that there is little association between hours of sleep and daytime } \\
\text { energy. Correct dysfunctional beliefs using the evidence and derive alternative and functional thoughts. } \\
\text { Light therapy is effective for clients who have eveningness tendencies or who have comorbid depression. } \\
\text { It is recommended that the client receives exposure to light within } 15 \text { minutes of wake for } 45 \text { minutes } \\
\text { through a lightbox or sunlight. }\end{array}$ \\
\hline
\end{tabular}

Adapted from Suh. Case Study Book of Cognitive-Behavioral Therapy for Insomnia 2017;6-9, with permission of sigmapress ${ }^{23}$

동과 관련이 있고, ${ }^{21}$ 정서 조절의 실패는 posttraumatic stress disorder(PTSD)를 유의하게 예측하고 PTSD의 발생, 지속, 악화에 영향을 미친다. ${ }^{22}$

수면 문제는 정서 조절 실패 및 정신질환과 밀접한 관계 가 있다. 구체적으로 기분장애의 정서 조절 실패를 수면 문 제가 더 악화시키거나, ${ }^{24}$ 범불안장애와 수면 문제의 관계를 정서 조절 실패가 매개하는 등의 관계가 확인되었다. ${ }^{25}$ 수면 과 정서는 양방향으로 영향을 주고받는 관계를 보이는데, ${ }^{26}$ 부정적인 정서 반응은 인지적, 신체적 각성을 매개하여 불면 증을 지속시키고, ${ }^{27}$ 낮은 수면의 질은 부정적인 정서에 대한 조절 능력을 손상시킨다. ${ }^{28}$ 수면이 정서 조절에 어떤 역할을 하는지에 대해서는 추가적인 연구가 필요하지만 수면 문제 가 정서 조절 실패에 독립적인 위험 요인임을 지지하는 근거 는 증가하고 있다. ${ }^{29}$

정서 조절과 자살 경향성의 관계에 관한 이전의 연구는 대 체로 정서 조절을 방해가 되는 감정, 특히 부정적인 감정을 조절하거나 없애는 단일적인 차원의 개념으로 보았다. ${ }^{30}$ 그 러나 이후의 연구는 정서 조절을 보다 다차원적인 개념으로 보고 정서 조절의 세부 항목과 자살 사고, 자살 행동과의 관 계를 확인하고자 하였다. ${ }^{31-33}$ 자살의 대인관계 이론을 기반 으로 정서 조절 실패의 역할을 확인하고자 했던 연구에서는 정서 조절 실패의 두 가지 구성 요소인 심리적 고통에 대한 역치(distress tolerance), 부정적인 감정을 조절하지 못해 무 분별하게 행동할 가능성(negative urgency)과 자살에 대한 갈망, 자살 행동의 관계를 확인하였다. 심리적 고통을 견딜 수 있는 역치가 낮고 부정적인 감정을 조절하지 못해 무분
별하게 행동할 가능성이 큰 사람들이 높은 수준의 자살 갈 망을 보였으나 자살의 대인관계 이론에서 자살을 실제로 실 현하기 위해 필요하다고 보았던 자살 실행 능력, 즉 자살 행 동의 수준은 낮았다. ${ }^{31}$ 우울 증상과 기분장애 여부를 통제한 후에도 심리적 고통을 느낄 때 효과적인 조절 방안의 부재 는 현재의 자살 사고를 예측하였고, ${ }^{32}$ 강렬한 부정적 정서인 좌절된 소속감이 불면증과 자살 사고의 관계를 매개하는 것 을 확인한 연구도 있다. ${ }^{34}$

불면증과 정서 조절 실패, 자살 위험성의 기제를 확인하기 위해서는 연구를 통한 경험적 근거가 필요하지만, 기존의 연 구들을 통해 불면증과 정서 조절의 실패가 상호작용을 통해 심화되고, 이로 인해 자살 사고 등의 자살 위험성에 영향을 줄 것이라는 가설은 검증해 볼 만한 것으로 생각되며 정서 조절의 어떤 요인이 자살 사고 혹은 자살 행동에 영향을 미 치는지 보다 정밀한 검증이 요구된다.

\section{무망감(Hopelessness)과 충동성}

자살 행동의 인지 모델에 의하면 정신질환에 취약한 소인 적 요인들이 스트레스 상황에서 역기능적인 인지 과정을 활 성화시키고, 이러한 인지 처리의 빈도, 기간, 강도가 심화되 면서 자살 관련 인지 도식이 활성화될 가능성이 커진다. 개 인이 감당할 수 있는 수준을 넘어서 고통스러운 생각과 정서 가 지속되면 자살과 관련된 인지는 결국 자살 행동으로 귀결 된다. 이 모델에서 소개한 정신질환에 취약한 소인적 요인에 는 충동성, 문제해결 능력의 결함 등이 해당되고, 무망감은 자살 관련 인지 도식 중 하나이다. ${ }^{35}$ 또한, 문제해결 능력의 
결함, 충동성, 판단력 부족, 무망감 등은 다른 연구에서도 자 살의 위험 인자로 확인된 인지적 요소이다. ${ }^{36-39}$ 불면증 환자 들이 호소하는 주간 기능의 어려움에서도 확인할 수 있는 것 처럼 수면 문제는 주간의 여러 인지 기능에 부정적 영향을 준다. 메타분석에 의하면 불면증은 여러 인지 기능 중 작업 기억, 일화기억, 문제해결 능력을 손상시킨다..$^{40}$ 이 외에도 49 시간의 수면 박탈이 미치는 영향을 확인한 연구에서는 수면 박탈 후에 더 위험한 의사결정을 하는 경향이 커지고, 연령 이 높을수록 이러한 경향이 두드러짐을 확인하였다..$^{41}$

가장 잘 알려진 자살의 인지적 위험 인자인 무망감은 자 신과 자신의 미래에 대한 부정적인 기대로 정의할 수 있다. ${ }^{42}$ 무망감은 우울과 자살 사고의 관계를 설명할 수 있는 기제로 써 작용하고, 충동성은 우울 심각도와 자살 사고의 관계성을 강화한다. ${ }^{43}$ 무망감은 또한 불면증과 자살 사고의 관계를 설명 할 수 있는 기제이기도 한데, 이 관계에서 우울의 영향을 통제하 고도 무망감은 여전히 자살 사고를 유의하게 예측하였다. ${ }^{4}$

자살은 충동적인 행동이라고 생각하기 쉽지만, 메타분석 에 의하면 계획 없이 시행된 충동적인 자살 시도는 치명적이 지 않은 결과를 야기하는 경향이 있었고 충동성과 자살의 관 계도 크지 않았다. 자살과의 관계에서 충동성은 부정적인 감 정을 느낄 때보다 빠르게 자살 사고를 경험하고, 자해 행동을 하게 하는 등 자살 실행 능력을 높이는 역할을 할 수 있다. ${ }^{45,46}$ 충동성과 자살의 관계를 확인한 연구에서는 충동성의 구성 개념을 구체화하여 그 관계를 확인하였다. Whiteside와 Lynam은 충동성의 4요인을 확인하였는데, 부정적인 정서를 느낄 때 강한 충동을 느끼는 경향(urgency), 행동의 결과를 숙고하는 능력의 결핍(lack of premeditation), 인내력의 부 족(lack of perseverance), 감각 추구(sensation seeking)가 이에 해당한다. ${ }^{47}$ 충동성은 각 요인이 자살 위험, 불면증과 맺 는 관계를 구분하여 볼 필요가 있다. 예를 들어, 자살 사고만 있는 사람과 자살 시도 과거력이 있는 사람은 모두 충동성의 한 요인인 부정적인 감정을 경험할 때 강한 충동을 보고했지 만, 자살 시도 과거력이 있는 집단만 또 다른 요인인 행동의 결과를 숙고하는 능력의 결핍이 유의했다. ${ }^{48}$ 불면증과의 관 계에서는, 각 요인 중 부정적 감정을 경험할 때 느끼는 강한 충동만 불면증의 심각도 및 주간 기능의 손상과 관련이 있 었고, 또 다른 요인인 인내력의 부족은 주간 기능의 손상과의 관계만 확인되었다. ${ }^{49}$ 충동성과 불면증의 기제는 불면증 환 자들이 입면 전에 취하는 두 가지 인지 처리 방식인 공격적 억압과 걱정을 통해서 설명할 수 있다..$^{50}$

\section{수면 시간의 영향}

불충분한 수면, 즉 짧은 수면 시간과 수면 스케줄도 자살
위험의 증가와 관계가 있다. 먼저 수면 시각에 관해서는, 불 면증뿐만 아니라 악몽 및 다른 수면장애들도 자살 위험과의 관계가 확인되었기 때문에 Perlis와 그의 동료들은 서로 다 른 수면 문제들에 공통적인 요인이 자살 위험을 높이는 데 에 기여할 것으로 보았다. 즉, 수면 문제는 밤에 깨어 있게 만드는데, 생물학적으로 준비되지 않은 시간에 깨어 있는 것 이 전두엽의 기능 저하(hypofrontality)를 야기하고, 집행 기 능을 감소시켜 자살 사고 및 자살 행동의 위험을 높인다는 개념적 모델을 제안하였다. 그리고 여러 문헌에 대한 검토를 통해 밤에 깨어 있는 것이 다른 시간에 깨어 있는 것보다 자 살 위험을 높이는 것을 확인하였다. ${ }^{51}$ 짧은 수면 시간이 자살 위험에 미치는 영향도 여러 연구를 통해 확인되었다. 먼저 국내의 8,530명의 청소년을 대상으로 한 연구에서는, 불충분 한 수면을 취하는 청소년들이 주중에 7시간 이상 자는 학생 들보다 자살 사고 수준이 높았다. 이는 연령, 성별, 우울을 통 제한 후에도 동일했다. 또한 주중에는 조금 자고, 주말에는 많이 자는 수면 패턴도 높은 수준의 자살 사고를 예측하였 다. ${ }^{52} 1,362$ 명의 중국 청소년을 대상으로 한 연구에서도 8시 간 미만의 짧은 수면이 연령, 성별, 우울 증상 등을 통제하고 도 자살 시도 위험의 증가와 관련 있었다..$^{33}$ 다른 연구에서는 8,090 명의 성인을 대상으로 5 시간 이하의 수면 시간과 자살 사고, 자살 시도와의 관계를 확인하였다. 불충분한 수면은 자살 사고와 자살 시도의 확률을 증가시켰고, 이는 인구통계 적 변인과 정신질환을 통제한 후에도 유의하였다. ${ }^{54}$ 성별에 따라 결과에 차이를 보인 연구도 있었는데, 자살 시도 과거 력이 있는 여성들이 남성에 비해 짧은 수면을 취했을 때(5시 간 이하) 자살 의도와 자살 위험이 유의하게 높아졌다. ${ }^{55}$ 연구 대상과 짧은 수면 시간의 정의가 연구마다 차이가 있지만, 불충분한 수면 외에 주중과 주말의 수면 시간에 차이가 큰 불규칙한 수면 스케줄 또한 청소년의 자살 위험을 높이는 데 영향을 줄 수 있으므로 수면의 어려움을 입체적으로 평가하 는 것이 중요하다.

\section{불면증 치료로 인한 자살 경감 효과}

불면증을 위한 인지행동치료를 통해 자살의 위험성을 줄 일 수 있는지 검증한 연구는 지금까지 2개 있었다(Table 2). 최근 Trockel 등의 연구에서는 불면 증상을 호소하는 405명 의 군인을 대상으로 불면증을 위한 인지행동치료를 시행하 여 자살 사고 경감에 효과가 있는지 확인하고자 총 6회기의 치료를 시행하였다. 치료 결과, 치료 전에는 128 명(32\%), 치 료 후에는 86명(21\%)의 참가자가 자살 사고를 보고하였고, 이는 $33 \%$ 의 자살 사고 감소를 의미했다. 또한, 이 연구에서 인구통계적 변인과 치료 전의 불면증 심각도를 통제한 후에 
Table 2. Studies of CBTI and treatment effects on suicide risk

\begin{tabular}{|c|c|c|c|c|}
\hline Citation & $\mathrm{n}$ & CBTI components & Session & Outcome \\
\hline Manber et al. ${ }^{57}$ & 301 & $\begin{array}{l}\text { Structured intervention } \\
\text { (Session 1) Education, mini intakes, goal setting } \\
\text { (Session 2) Psycho-education, sleep hygiene } \\
\text { (Session 3, 4, 5) Stimulus control, sleep restriction treatment, } \\
\text { scheduled worry time, cognitive restructuring } \\
\text { (Session 6) Relaxation training } \\
\text { (Session 7) Relapse prevention }\end{array}$ & $\begin{array}{l}7 \text { sessions of } \\
\text { group CBTI }\end{array}$ & $\begin{array}{l}\text { Suicidal ideation decreased } \\
\text { by } 57 \%(p<0.0001) \\
\text { BDI suicide item }\end{array}$ \\
\hline Trockel et al. ${ }^{56}$ & 405 & $\begin{array}{l}\text { Tailoring treatment components based on case } \\
\text { conceptualization } \\
\text { Sleep restriction treatment } \\
\text { Stimulus control } \\
\text { Relaxation exercises } \\
\text { Cognitive therapy }\end{array}$ & $\begin{array}{l}6 \text { sessions } \\
\text { (including initial } \\
\text { assessment } \\
\text { session) }\end{array}$ & $\begin{array}{l}\text { Suicidal ideation decreased } \\
\text { by } 33 \%(p<0.001) \\
\text { BDI-II suicide item }\end{array}$ \\
\hline
\end{tabular}

CBTI: cognitive-behavioral therapy for insomnia, BDI: Beck depression inventory

도 불면증 심각도 척도 점수 7 점의 감소는 $65 \%$ 의 자살 사고 감소와 관련이 있었다. 불면증의 개선에 따른 우울 증상의 개선도 함께 확인되었고, 우울 증상의 개선을 통제하고도 불 면증의 개선이 자살 사고의 감소에 미치는 영향은 여전히 유의했다. ${ }^{56}$

Manber와 동료들의 연구에서는 우울 증상 심각도에 따른 불면증을 위한 인지행동치료의 반응에 대해 살펴보았다. 이 연구에서는 301 명의 참가자들이 불면증을 위한 인지행동치 료를 받고 난 이후, 우울, 자살 사고 등 수면 이외의 결과에서 증상 경감을 확인했으며, 치료 전에 자살 생각이 있다고 대 답한 환자의 $45 \%$ 는 불면증 치료 후에는 자살 생각이 전혀 없다고 응답하였다. ${ }^{57}$

불면증의 인지행동치료가 자살 위험을 감소시키는 기제 에 대해서는 기존 문헌들을 토대로 크게 세 가지의 가설을 생각해 볼 수 있다. 첫째, 불면증 치료를 통해 자살 위험성이 높은 정신질환 증상이 완화되어 자살 위험이 경감될 수 있 을 것이다. 연구를 통해 확인된 자살의 여러 위험 요인 중 정 신질환은 자살과 가장 강력한 관계가 있는 요인이었고 ${ }^{58}$ 특 히 주요 우울장애, 양극성 장애, 외상후 스트레스장애, 알코 올사용장애 등이 자살 위험이 높은 장애로 알려져 있다. 수면 문제는 위에 언급된 정신질환을 포함하여 많은 정신질환의 증상이며, 불면이나 과다수면 등의 문제 외에도 외상후 스트 레스장애의 악몽이나, 공황장애의 야간 공황발작 등 정신질 환의 구체적 증상과 관련된 수면 문제도 특정 정신질환에서 동반될 수 있는 증상이다. ${ }^{59}$ 이러한 수면 관련 증상은 불면증 과 정신질환을 악화시키고, 치료되지 않은 수면 문제는 정신 질환의 치료 반응을 저해할 수 있다. ${ }^{60,61}$ 심리치료의 반응성 연구에 의하면 수면 문제는 치료 반응이 가장 느린 증상에 속 하기도 하고, ${ }^{2}$ 정신질환의 다른 증상이 개선된다고 해도 수
면 문제는 잔여 증상으로 남아 있는 경우가 많다. 즉, 정신질 환은 물론 동반되는 수면 문제의 개선을 위해서는 수면 문제 에 대한 독립적인 개입이 요구된다.

최근에는 다양한 정신질환에서 불면증이 공존하는 환자들 에게 불면증을 위한 인지행동치료를 시행하여 수면 외의 증 상에서도 치료 효과를 확인하였다. 외상후 스트레스장애 환 자들에게 8회기의 불면증을 위한 인지행동치료를 시행한 후 에 수면의 개선과 심리 사회적 기능의 향상을 확인할 수 있었 고 이러한 효과는 6 개월 이후 추적 연구에서도 유지되었다. ${ }^{63}$ 다른 연구에서는 양극성 장애에 특징적인 수면 양상에 개입 하고 치료의 안전성을 높이기 위해 불면증의 인지행동치료 를 보완하여 총 8회기의 치료를 시행하였는데 심리 교육만 실시한 대조군에 비해 불면증의 인지행동치료를 받은 집단 에서 더 짧은 조증 삽화와, 유의하게 낮은 경조증/조증의 재 발 비율을 확인하였다. 6 개월 후에도 치료의 효과는 대부분 잘 유지되었다. ${ }^{64}$ 주요 우울장애와 불면증이 공존하는 경우에 도 항우울제와 불면증을 위한 인지행동치료를 함께 시행하 는 것이 항우울제만 처방하는 것보다 우울과 불면 증상에 더 효과적이었다. ${ }^{65}$ 불면증을 위한 인지행동치료를 시행할 때 정신질환이 공존하는 경우 치료 동기나 심리적 자원을 우려 할 수 있지만, 메타분석에 의하면 수면 효율에 대한 치료 반 응은 공존하는 정신질환이 없는 집단보다 정신질환이 공존 하는 경우 더 좋았다. ${ }^{66}$ 대부분의 경우에 불면증은 다른 질환 과 공존하고 그중 정신질환은 자살 위험 인자로 작용할 수 있다. 불면증의 인지행동치료를 통해 동반되는 수면 문제의 경감, 치료 반응성의 개선, 정신질환 증상의 경감을 기대할 수 있으며 이를 통해 자살 위험을 낮추는 데 기여할 수 있을 것이다.

둘째, 만성질환의 위험이 높아지는 중년층 이상의 집단에 
게는 불면증 치료를 통한 신체질환의 개선도 자살 위험 경 감을 설명할 수 있는 요인일 것이다. 불충분한 수면, 열악한 수면의 질 등 수면 문제가 질병 위험과 사망률을 높인다는 것 은 이미 잘 알려진 사실이다. 39,67-69 수면 문제는 신체에 만성 적 스트레스 요인으로 작용하여 대사작용, 심혈관계, 면역체 계 등 다양한 조절 체계에 누적되는 부담으로 작용할 수 있 다. ${ }^{70-73}$ 이는 특히 신체질환의 위험이 커지는 중년층 이상의 집단에게 중요한 요인으로 생각되며, 신체질환은 우울 및 알 코올 사용과 독립적으로 자살 경향성과 관계가 있고, ${ }^{74}$ 정신 장애와 동반되지 않아도 자살 행동의 위험 요인이다. ${ }^{75}$ 따라 서 불면증의 인지행동치료를 통해 신체질환의 위험성이 낮 아진다면 자살 경향성도 경감될 것이라고 추측해 볼 수 있다. ${ }^{4}$ 불면증의 인지행동치료를 통한 신체질환 위험성의 경감은 연구를 통해 확인된 바 있다. Irwin 등은 123 명의 만성 불면 증 노인들을 대상으로 불면증을 위한 인지행동치료를 시행 했는데, 치료를 통해 다양한 수면 지표, 우울, 피로의 개선과 함께 심혈관계 질환 및 당뇨와 관련된 염증 위험의 지표가 될 수 있는 C-reactive protein 수준도 감소하였다..$^{76}$ 또 다른 연구에서 55세 이상의 불면증 환자를 대상으로 심혈관계 질 환, 대사성 질환 및 염증성 질환의 위험과 관련된 8개의 생 리적 지표(biomarker)를 확인하고 불면증을 위한 인지행동 치료를 시행하였는데, 1 년 후에 연구 시작 당시 높은 수준의 생물학적 지표를 확인했던 피험자들에게서 그 수준이 감소 됨을 확인할 수 있었다. ${ }^{70}$

셋째, 불면증 증상의 개선을 통해 자살 위험으로 이어질 수 있는 기제가 약화되어 자살 위험이 경감될 수 있을 것이 다. 불면증을 위한 인지행동치료는 행동적, 인지적, 교육적 요소로 구성된 치료이다. 행동과 정서, 인지는 상호 간에 영 향을 주고받기 때문에, 불면증을 위한 인지행동치료를 통한 개입은 수면과 관련된 정서, 인지, 행동 모두에 유기적으로 영향을 줄 수 있다. 불면증을 위한 인지행동치료를 통한 인 지적 개입의 효과성은 연구를 통해서도 검증되었다. Edinger 와 그의 동료들은 불면증 환자들을 수면 관련 역기능적 신념 과 자기 효능감이 낮은 집단과 높은 집단으로 구분하여 8주 간 불면증을 위한 인지행동치료를 시행하였다. ${ }^{77}$ 수면과 관 련된 인지적 무력감 수준이 높은 집단이 더 좋은 치료 효과 성을 보였는데 이를 통해 수면에 대한 인지적 개입의 필요 성과 치료의 효과성을 확인할 수 있다. 불면증의 인지행동치 료의 인지적 접근은 불면증을 지속시키는 걱정과 반추, 수면 관련 주의 편향, 수면에 관한 역기능적인 신념과 이를 지속 시키는 안전 행동, 수면과 주간 기능 손상에 대한 오해 등을 다루며 기본적인 원리와 기법은 다른 장애에 적용되는 것과 비슷하다. ${ }^{78}$ 필수적인 생물학적 과정인 수면의 어려움이 지
속될수록 수면에 대한 무망감이 만연해지고 동반되는 부정 적 정서는 강한 충동을 야기할 수 있으며, 이는 자살 위험을 높이는 역할을 할 수 있다. ${ }^{20}$ 불면증을 위한 인지행동치료를 통해 역기능적 인지와 동반되는 부정적 정서가 개선된다면 간접적으로 자살 위험으로 이어질 수 있는 기제가 약화될 것 을 기대할 수 있다. ${ }^{27,79}$ 또한, 불면증을 위한 인지행동치료의 행동적 요소는 침대에 머무는 시간, 낮잠 등을 줄이고 수면 스케줄의 큰 변산성을 줄이는 과정을 통해 불규칙한 수면 스케줄과 수면 시간, 수면 효율 등을 개선시킬 수 있으므로 짧은 수면 시간과 불규칙한 스케줄로 인해 높아지는 자살 위험성에 개입하는 효과가 있다. ${ }^{80}$

\section{결 론}

수면 문제가 자살의 위험성을 높이는 독립적인 요인임을 지지하는 근거는 증가하고 있고, 불면증의 인지행동치료를 통해 수면 문제를 개선시켰을 때 자살 위험이 경감하는 것은 더 많은 연구를 통한 경험적인 근거가 필요하지만 충분히 기 대할 수 있는 효과로 보인다. 수면 문제는 자살의 위험 인자 로 알려진 다른 요인들에 비해 개입을 통한 변화가 가능하 고, 정신질환 등에 비하면 낙인 가능성이 낮은 문제에 속한 다. 또한 불면증의 인지행동치료는 4 8회기 정도로 구성되 어 비교적 짧은 회기로 효과를 기대할 수 있기 때문에 효율 적이다. 정신질환이나 다른 신체질환에 비하면 치료의 진입 장벽이 낮아 초기 개입이 보다 용이한 특징이 있으며, 수면을 다루면서 다른 위험 요인의 탐색과 지속적 모니터링이 가능 한 장점이 있다.

자살 위험에 대한 평가를 할 때 수면 문제도 함께 평가되 어야 하며, 이는 자살 위험성에 대한 평가일 뿐 아니라 개입 의 잠재적 타깃을 구체화하는 과정이기도 하다. 수면에 대한 평가는 수면의 질과 수면 유지에 대한 내용이 포함되어야 하 며, 수면 시간, 수면 스케줄 등 수면의 어려움을 다각도로 평 가할 필요가 있다. ${ }^{7.52}$ 자살 위험이 높은 정신질환의 치료 과 정에서도 수면의 어려움을 지속적으로 평가해야 하며, 수면 문제가 있을 경우 이에 대한 독립적인 개입이 필요하다. 또 한 수면의 갑작스러운 변화가 감지된다면 그러한 변화가 자 살의 취약성을 의미할 수 있음을 인지하고 자살 위험성에 대한 평가를 반드시 시행해야 한다.

불면증과 자살의 관계에 관한 최근 리뷰 논문에서는 불면 증과 자살 사고, 자살 행동의 분류와 평가에 관한 연구들의 비일관성을 지적하였다. ${ }^{20}$ Silverman과 그의 동료들은 O'Carroll 등이 제안한 자살 연구의 체계적인 명명법을 개정하여 자살의 개념을 구체화하고자 하였다. ${ }^{81,82}$ 이 분류에 따르면 
자살 관련 행동은 자살 의도의 수준과 자살 행동으로 인한 결과의 치명성의 수준에 따라 세분화할 수 있는데, 추후에 자살 위험성에 대한 평가를 할 때에도 제시된 분류체계에 따라 자살 사고 혹은 자살 행동의 위험성을 구체적으로 평 가하는 일이 필요할 것으로 생각된다.

\section{Acknowledgments}

This work was supported by the Sungshin University Research Grant of 2017 (2016-2-11-024)

\section{REFERENCES}

1. World Health Organization. Suicide data. [cited 2017 Nov 28]. Available from URL: http://www.who.int/mental_health/prevention/suicide/suicideprevent/en/.

2. Statistics Korea. Causes of death statistics in 2016. [cited 2017 Nov 28]. Available from URL: http://kostat.go.kr/portal/eng/pressReleases/1/ index.board? bmode $=$ read\&aSeq $=363695$.

3. Bernert RA, Nadorff MR. Sleep disturbances and suicide risk. Sleep Med Clin 2015;10:35-39.

4. Bishop TM, Simons KV, King DA, Pigeon WR. Sleep and suicide in older adults: an opportunity for intervention. Clin Ther 2016;38:23322339.

5. Klimkiewicz A, Bohnert AS, Jakubczyk A, Ilgen MA, Wojnar M, Brower $\mathrm{K}$. The association between insomnia and suicidal thoughts in adults treated for alcohol dependence in Poland. Drug Alcohol Depend 2012;122:160-163.

6. Wong MM, Brower KJ. The prospective relationship between sleep problems and suicidal behavior in the National Longitudinal Study of Adolescent Health. J Psychiatr Res 2012;46:953-959.

7. Malik S, Kanwar A, Sim LA, et al. The association between sleep disturbances and suicidal behaviors in patients with psychiatric diagnoses: a systematic review and meta-analysis. Syst Rev 2014;3:18.

8. Fujino Y, Mizoue T, Tokui N, Yoshimura T. Prospective cohort study of stress, life satisfaction, self-rated health, insomnia, and suicide death in Japan. Suicide Life Threat Behav 2005;35:227-237.

9. Ribeiro JD, Pease JL, Gutierrez PM, et al. Sleep problems outperform depression and hopelessness as cross-sectional and longitudinal predictors of suicidal ideation and behavior in young adults in the military. J Affect Disord 2012;136:743-750.

10. McCall WV, Blocker JN, D’Agostino R Jr, et al. Insomnia severity is an indicator of suicidal ideation during a depression clinical trial. Sleep Med 2010;11:822-827.

11. Yoshimasu K, Sugahara H, Akamine M, et al. Sleep disorders and suicidal ideation in Japanese patients visiting a psychosomatic clinic in a university hospital. Sleep Biol Rhythms 2006;4:137-143.

12. Pigeon WR, Pinquart M, Conner K. Meta-analysis of sleep disturbance and suicidal thoughts and behaviors. J Clin Psychiatry 2012;73: e1160-e1167.

13. Linehan MM. Suicide intervention research: a field in desperate need of development. Suicide Life Threat Behav 2008;38:483-485.

14. Glenn CR, Cha CB, Kleiman EM, Nock MK. Understanding suicide risk within the Research Domain Criteria (RDoC) framework: insights, challenges, and future research considerations. Clin Psychol Sci 2017; 5:568-592.

15. Spielman AJ, Caruso LS, Glovinsky PB. A behavioral perspective on insomnia treatment. Psychiatr Clin North Am 1987;10:541-553.

16. Smith MT, Smith LJ, Nowakowski S, Perlis ML. Primary insomnia: diagnostic issues, treatment, and future directions. In: Perlis ML, Lichstein KL. Treating sleep disorders: principles and practice of Behavioral Sleep Medicine. 1st ed. Hoboken: John Wiley \& Sons, Inc., 2003;214-261.

17. Lack LC, Bootzin R. Circadian rhythm factors in insomnia and their treatment. Hoboken: John Wiley \& Sons, Inc., 2003.

18. Lewy AJ, Sack RA, Singer CL. Assessment and treatment of chronobiologic disorders using plasma melatonin levels and bright light exposure: the clock-gate model and the phase response curve. Psychopharmacol Bull 1984;20:561-565.

19. Woznica AA, Carney CE, Kuo JR, Moss TG. The insomnia and suicide link: toward an enhanced understanding of this relationship. Sleep Med Rev 2015;22:37-46.

20. Cho YR. Assessing emotion dysregulation: psychometric properties of the Korean version of the difficulties in emotion regulation scale. Korean Journal of Clinical Psychology 2007;26:1015-1038.

21. Silk JS, Steinberg L, Morris AS. Adolescents' emotion regulation in daily life: links to depressive symptoms and problem behavior. Child Dev 2003;74:1869-1880.

22. Weiss NH, Tull MT, Anestis MD, Gratz KL. The relative and unique contributions of emotion dysregulation and impulsivity to posttraumatic stress disorder among substance dependent inpatients. Drug Alcohol Depend 2013;128:45-51.

23. Suh S. Case Study Book of Cognitive-Behavioral Therapy for Insomnia. Seoul: sigmapress, 2017:6-9.

24. Cukrowicz KC, Otamendi A, Pinto JV, Bernert RA, Krakow B, Joiner TE Jr. The impact of insomnia and sleep disturbances on depression and suicidality. Dreaming 2006;16:1-10.

25. Tsypes A, Aldao A, Mennin DS. Emotion dysregulation and sleep difficulties in generalized anxiety disorder. J Anxiety Disord 2013;27:197203.

26. Kahn M, Sheppes G, Sadeh A. Sleep and emotions: bidirectional links and underlying mechanisms. Int J Psychophysiol 2013;89:218-228.

27. Baglioni C, Spiegelhalder K, Lombardo C, Riemann D. Sleep and emotions: a focus on insomnia. Sleep Med Rev 2010;14:227-238.

28. Mauss IB, Troy AS, LeBourgeois MK. Poorer sleep quality is associated with lower emotion-regulation ability in a laboratory paradigm. Cogn Emot 2013;27:567-576.

29. Ennis CR, Short NA, Moltisanti AJ, Smith CE, Joiner TE, Taylor J. Nightmares and nonsuicidal self-injury: the mediating role of emotional dysregulation. Compr Psychiatry 2017;76:104-112.

30. Thompson RA. Emotion regulation: a theme in search of definition. Monogr Soc Res Child Dev 1994;59:25-52.

31. Anestis MD, Bagge CL, Tull MT, Joiner TE. Clarifying the role of emotion dysregulation in the interpersonal-psychological theory of suicidal behavior in an undergraduate sample. J Psychiatr Res 2011;45:603-611.

32. Rajappa K, Gallagher M, Miranda R. Emotion dysregulation and vulnerability to suicidal ideation and attempts. Cognit Ther Res 2012;36: 833-839.

33. Weinberg A, Klonsky ED. Measurement of emotion dysregulation in adolescents. Psychol Assess 2009;21:616-621.

34. Chu C, Hom MA, Rogers ML, et al. Is insomnia lonely? Exploring thwarted belongingness as an explanatory link between insomnia and suicidal ideation in a sample of South Korean University students. $J$ Clin Sleep Med 2016;12:647-652.

35. Wenzel A, Beck AT. A cognitive model of suicidal behavior: theory and treatment. Appl Prev Psychol 2008;12:189-201.

36. Bridge JA, McBee-Strayer SM, Cannon EA, et al. Impaired decision making in adolescent suicide attempters. J Am Acad Child Adolesc Psychiatry 2012;51:394-403.

37. Ellis TE, Rutherford B. Cognition and suicide: two decades of progress. Int J Cogn Ther 2008;1:47-68.

38. McMillan D, Gilbody S, Beresford E, Neilly L. Can we predict suicide and non-fatal self-harm with the Beck Hopelessness Scale? A metaanalysis. Psychol Med 2007;37:769-778.

39. Van Orden KA, Witte TK, Cukrowicz KC, Braithwaite SR, Selby EA, Joiner TE Jr. The interpersonal theory of suicide. Psychol Rev 2010;117: 575-600.

40. Fortier-Brochu E, Beaulieu-Bonneau S, Ivers H, Morin CM. Insomnia and daytime cognitive performance: a meta-analysis. Sleep Med Rev 
2012;16:83-94.

41. Killgore WD, Balkin TJ, Wesensten NJ. Impaired decision making following 49 h of sleep deprivation. J Sleep Res 2006;15:7-13.

42. Beck AT, Weissman A, Lester D, Trexler L. The measurement of pessimism: the hopelessness scale. J Consult Clin Psychol 1974;42:861-865.

43. Wang YY, Jiang NZ, Cheung EF, Sun HW, Chan RC. Role of depression severity and impulsivity in the relationship between hopelessness and suicidal ideation in patients with major depressive disorder. $J$ Affect Disord 2015;183:83-89.

44. Woosley JA, Lichstein KL, Taylor DJ, Riedel BW, Bush AJ. Hopelessness mediates the relation between insomnia and suicidal ideation. $J$ Clin Sleep Med 2014;10:1223-1230.

45. Anestis MD, Joiner TE. Examining the role of emotion in suicidality: negative urgency as an amplifier of the relationship between components of the interpersonal-psychological theory of suicidal behavior and lifetime number of suicide attempts. J Affect Disord 2011;129:261-269.

46. Anestis MD, Soberay KA, Gutierrez PM, Hernández TD, Joiner TE. Reconsidering the link between impulsivity and suicidal behavior. Pers Soc Psychol Rev 2014;18:366-386.

47. Whiteside SP, Lynam DR. The Five Factor Model and impulsivity: using a structural model of personality to understand impulsivity. Pers Individ Dif 2001;30:669-689.

48. Klonsky ED, May A. Rethinking impulsivity in suicide. Suicide Life Threat Behav 2010;40:612-619.

49. Schmidt RE, Gay P, Van der Linden M. Facets of impulsivity are differentially linked to insomnia: evidence from an exploratory study. Behav Sleep Med 2008;6:178-192.

50. Schmidt RE, Gay P, Ghisletta P, Van Der Linden M. Linking impulsivity to dysfunctional thought control and insomnia: a structural equation model. J Sleep Res 2010;19(1 Pt 1):3-11.

51. Perlis ML, Grandner MA, Chakravorty S, Bernert RA, Brown GK, Thase ME. Suicide and sleep: is it a bad thing to be awake when reason sleeps? Sleep Med Rev 2016;29:101-107.

52. Lee YJ, Cho SJ, Cho IH, Kim SJ. Insufficient sleep and suicidality in adolescents. Sleep 2012;35:455-460.

53. Liu X. Sleep and adolescent suicidal behavior. Sleep 2004;27:13511358.

54. Goodwin RD, Marusic A. Association between short sleep and suicidal ideation and suicide attempt among adults in the general population. Sleep 2008;31:1097-1101.

55. Blasco-Fontecilla H, Alegria AA, Lopez-Castroman J, et al. Short selfreported sleep duration and suicidal behavior: a cross-sectional study. J Affect Disord 2011;133:239-246.

56. Trockel M, Karlin BE, Taylor CB, Brown GK, Manber R. Effects of cognitive behavioral therapy for insomnia on suicidal ideation in veterans. Sleep 2015;38:259-265.

57. Manber R, Bernert RA, Suh S, Nowakowski S, Siebern AT, Ong JC. CBT for insomnia in patients with high and low depressive symptom severity: adherence and clinical outcomes. J Clin Sleep Med 2011;7:645652.

58. Cavanagh JT, Carson AJ, Sharpe M, Lawrie SM. Psychological autopsy studies of suicide: a systematic review. Psychol Med 2003;33:395-405.

59. American Psychiatric Association. Diagnostic and Statistical Manual of Mental Disorders, Fifth Edition (DSM-5). Washington, DC: American Psychiatric Association, 2013;947.

60. Smith MT, Huang MI, Manber R. Cognitive behavior therapy for chronic insomnia occurring within the context of medical and psychiatric disorders. Clin Psychol Rev 2005;25:559-592.

61. Taylor DJ, Pruiksma KE. Cognitive and behavioural therapy for insomnia (CBT-I) in psychiatric populations: a systematic review. Int Rev Psychiatry 2014;26:205-213.

62. Kopta SM, Howard KI, Lowry JL, Beutler LE. Patterns of symptomatic recovery in psychotherapy. J Consult Clin Psychol 1994;62:1009-1016.
63. Talbot LS, Maguen S, Metzler TJ, et al. Cognitive behavioral therapy for insomnia in posttraumatic stress disorder: a randomized controlled trial. Sleep 2014;37:327-341.

64. Harvey AG, Soehner AM, Kaplan KA, et al. Treating insomnia improves mood state, sleep, and functioning in bipolar disorder: a pilot randomized controlled trial. J Consult Clin Psychol 2015;83:564-577.

65. Manber R, Edinger JD, Gress JL, et al. Cognitive behavioral therapy for insomnia enhances depression outcome in patients with comorbid major depressive disorder and insomnia. Sleep 2008;31:489-495.

66. McCall WV. Cognitive behavioral therapy for insomnia (CBT-I): what is known, and advancing the science by avoiding the pitfalls of the placebo effect. Sleep Med Rev 2017 May 5. pii: S1087-0792(17)30090-4. [Epub ahead of print] http://doi.org/10.1016/j.smrv.2017.05.001.

67. Cappuccio FP, D’Elia L, Strazzullo P, Miller MA. Sleep duration and all-cause mortality: a systematic review and meta-analysis of prospective studies. Sleep 2010;33:585-592.

68. Kojima M, Wakai K, Kawamura T, et al. Sleep patterns and total mortality: a 12-year follow-up study in Japan. J Epidemiol 2000;10:87-93.

69. Rod NH, Kumari M, Lange T, Kivimäki M, Shipley M, Ferrie J. The joint effect of sleep duration and disturbed sleep on cause-specific mortality: results from the Whitehall II cohort study. PLoS One 2014; 9:e91965.

70. Carroll JE, Seeman TE, Olmstead R, et al. Improved sleep quality in older adults with insomnia reduces biomarkers of disease risk: pilot results from a randomized controlled comparative efficacy trial. Psychoneuroendocrinology 2015;55:184-192.

71. Chen X, Redline S, Shields AE, Williams DR, Williams MA. Associations of allostatic load with sleep apnea, insomnia, short sleep duration, and other sleep disturbances: findings from the National Health and Nutrition Examination Survey 2005 to 2008. Ann Epidemiol 2014;24: 612-619.

72. McEwen BS, Karatsoreos IN. Sleep deprivation and circadian disruption: stress, allostasis, and allostatic load. Sleep Med Clin 2015;10:1-10.

73. Redline S, Foody J. Sleep disturbances: time to join the top 10 potentially modifiable cardiovascular risk factors? Circulation 2011;124: 2049-2051.

74. Druss B, Pincus H. Suicidal ideation and suicide attempts in general medical illnesses. Arch Intern Med 2000;160:1522-1526.

75. Scott KM, Hwang I, Chiu WT, et al. Chronic physical conditions and their association with first onset of suicidal behavior in the world mental health surveys. Psychosom Med 2010;72:712-719.

76. Irwin MR, Olmstead R, Carrillo C, et al. Cognitive behavioral therapy vs. Tai Chi for late life insomnia and inflammatory risk: a randomized controlled comparative efficacy trial. Sleep 2014;37:1543-1552.

77. Edinger JD, Carney CE, Wohlgemuth WK. Pretherapy cognitive dispositions and treatment outcome in cognitive behavior therapy for insomnia. Behav Ther 2008;39:406-416.

78. Harvey AG, Sharpley AL, Ree MJ, Stinson K, Clark DM. An open trial of cognitive therapy for chronic insomnia. Behav Res Ther 2007;45: 2491-2501.

79. Winsper C, Tang NK. Linkages between insomnia and suicidality: prospective associations, high-risk subgroups and possible psychological mechanisms. Int Rev Psychiatry 2014;26:189-204.

80. Schwartz DR, Carney CE. Mediators of cognitive-behavioral therapy for insomnia: a review of randomized controlled trials and secondary analysis studies. Clin Psychol Rev 2012;32:664-675.

81. O'Carroll PW, Berman AL, Maris RW, Moscicki EK, Tanney BL, Silverman MM. Beyond the Tower of Babel: a nomenclature for suicidology. Suicide Life Threat Behav 1996;26:237-252.

82. Silverman MM, Berman AL, Sanddal ND, O'Carroll PW, Joiner Jr. TE. Rebuilding the Tower of Babel: a revised nomenclature for the study of suicide and suicidal behaviors part 1: background, rationale, and methodology. Suicide Life Threat Behav 2007;37:248-263. 